\title{
Correction to: CRT Survey II: a European Society of Cardiology (ESC) survey of cardiac resynchronization therapy - an Irish subset analysis
}

\section{Deepti Ranganathan ${ }^{1} \cdot$ Zain Sharif $^{1}$ (1) $\cdot$ Theodore Murphy $^{1} \cdot$ Nial Mahon $^{2} \cdot$ Conor R. Sheahan $^{1} \cdot$ Camilla Normand $^{3,4}$. Cecilia Linde ${ }^{4,5} \cdot$ Kenneth Dickstein ${ }^{3,4} \cdot$ Ricky Sheahan $^{1}$}

Published online: 6 February 2020

(C) Royal Academy of Medicine in Ireland 2020

Correction to: Irish Journal of Medical Science (2020) https://doi.org/10.1007/s11845-020-02173-y

In the original version of this article, the author list contained a number of errors, namely a missing author name, and author names that had been merged incorrectly. The author list has been corrected. The original article has been corrected.

The online version of the original article can be found at https://oi.org/ 10.1007/s11845-020-02173-y

Zain Sharif

zainsharif@ rcsi.ie

Beaumont Hospital Dublin, Dublin, Ireland

2 Mater Misericordiae University Hospital, Dublin, Ireland

3 Cardiology Division, Stavanger University Hospital,

Stavanger, Norway

4 Institute of Internal Medicine, Bergen Stavanger University Hospital, University of Bergen, Bergen, Norway

5 Karolinska University Hospital, Stockholm, and Karolinska Institutet, Stockholm, Sweden 